\title{
The Influence of Politics on Accountability of Health Professionals in Bangladesh: An Analysis of the Quality of Health Service Delivery
}

\author{
M Islam
}

\begin{abstract}
This study explored the role and responsibility of elected officials including political actors and addressed the factors of politics, decentralisation, bureaucratic management, and political commitment to understanding accountability in health service delivery. This study used qualitative case studies for which a total of 68 in-depth interviews and five focus group discussions were conducted in two areas of rural and urban Bangladesh. The findings show that political actors have poor commitment to improving accountability and healthcare delivery. The elected officials are not interested in organising regular meetings and they are even reluctant to organise a health service committee to make health officials accountable. The opposition political parties have no participation in health service organisations as the existing political
\end{abstract}

culture does not allow it. Moreover, elected officials have a limited administrative authority because of an inadequate decentralised health system that leads to poor accountability and inadequate healthcare delivery. Further, bureaucrats want to capture power and are unwilling to decentralise the health system. The policy recommendation includes the decentralisation of healthcare provision and increased participation of elected representatives in a decentralised system.

Abbreviations: ADP - Annual Development Plan; MP - Member of Parliament; NGO - Non Government Organisation; UHC - Upazilia Health Complex; UP - Upazilia Parishad.

Key words: politics; elected officials; decentralisation; accountability; quality of healthcare.

\section{Mohammad Islam}

Public Administration

Shahjalal University

Sylhet 3114, Bangladesh.

\section{Correspondence:}

shafig.pad@gmail.com

\section{Introduction}

The quantitative indicators of maternal and child health in Bangladesh have improved significantly over the last several years. Data from the World Bank [1] show that the Maternal Mortality Ratio declined from 322 per 100,000 live births in 2001 to 170 in 2013. Life expectancy at birth increased from 45 years in 1970 to 70 years in 2013, and the Infant Mortality Rate declined from 94 per 1,000 live births in 1990 to 33 in 2013.
However, the quality of health service delivery is still inadequate. [2] Quality of healthcare is defined as the degree to which health services for individuals and populations is consistent with current professional knowledge and standards, and increases the likelihood of desired health outcomes. [3] A number of components enable patients to achieve desired health outcomes e.g., affordability, accessibility, efficiency, effectiveness and utilisation comprise quality health services. $[4,5]$

This study used maternal health as indicators to understand the influence of accountability on the quality of health service delivery, as the maternal health indicators have changed significantly during the last decade. Moreover, the health service organisations used as cases in this study are mainly maternal and child health as those services are very crucial to healthcare delivery in Bangladesh. In addition, no other studies based on maternal health services have been used for understanding accountability in Bangladesh. 


\section{Demographics and health status}

Health services are organised under the supervision of the Ministry of Health and Family Welfare, a centralised and bureaucratic organisation, headed by a cabinet minister. This organisation is responsible for implementing, managing, coordinating and regulating health service delivery, which is divided into two branches - health services and family planning - administered by separate directorates. [6] Primary healthcare is not free, but requires only a very small fee for service as defined under government provisions. This healthcare is provided through a four-tiered system of government owned and staffed facilities at the union' (lowest administrative unit) level all the way up to the central/regional level, [7] which is based on an administrative hierarchy. Locally elected officials are able to supervise health officials in improving health services; however they have no administrative authority to take action in implementing health services. The local health service bureaucracy, which is structured by hierarchy, is mainly responsible for implementing health activities.
The health service department at an upazila, the second lowest tier of regional administration, provides services through the upazila health complex (UHC). A UHC has under it union sub-centres and community clinics as the lowest tier of administrative unit (ward level). [8] Domiciliary services e.g., services at the patients' homes, are provided through field staff from the Department of Health service organisations in order to make health services accessible to grassroots people. The upazila health administrator (that is, the upazila health and family planning officer) is mainly responsible for guiding health staff including field workers to promote the quality of healthcare. [8]

${ }^{1}$ Union Councils (or Union Parishads or Town Unions or Unions) are the smallest rural administrative and local government units in Bangladesh. (Khan, Dr. Mohammad Ibrahim. 'Functioning of Local Government (Union Parishad): Legal and Practical Constraints' Democracy Watch.

\section{Figure 1: Administrative Hierarchy of the Health System in Bangladesh}

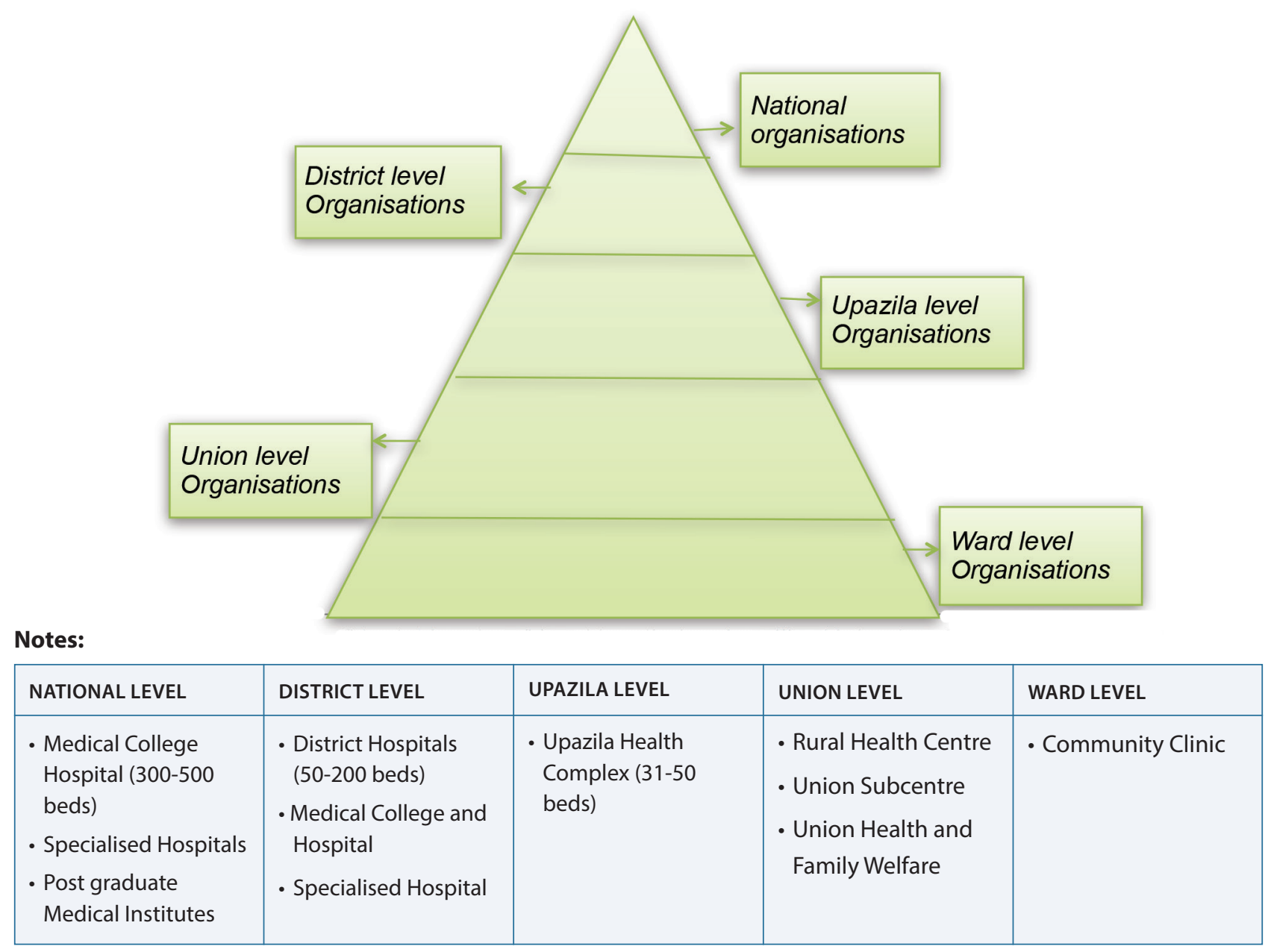

Source: Directorate of Health Services (2011, p. 13) 


\section{Organisations}

Osman [9] states that sources of finance for the health sectors in Bangladesh consist of a combination of different elements, which include households, government revenue, donors and the community through non-government organisations (NGOs). Osman [9] also states that the majority of health expenditure comes from households, accounting for 45.6 per cent of the total health expenditure in Bangladesh in 2006. Of the remaining expenditure, 26.6 per cent comes from government revenue, 25.8 per cent from external donors, and two per cent from community sources through NGOs. Osman [9] further states that a donor consortium², led by the World Bank, provides financial and technical assistance on a continuous basis to the health sector of Bangladesh that could contribute to enhancing the governance of health service organisations.

Scarcity of skilled health professionals is one of the challenges of adequate facilities of health service organisations in Bangladesh. Rahman et al [10] argue that Bangladesh has a shortage of health service personnel with only 246 physicians and 136 nurses per one million populations in 2005. This means that there is one doctor for 4,065 people on average, and one nurse for 7,353 people on average in 2005. In 2013, the ratio of physicians improved $(1: 3,297)$ but the nurse ratio decreased $(1: 11,696)$. [8]

One of the criteria of improved service delivery of health service organisations is the amount of money allocated by the government. The government Annual Development Program (ADP) report shows that the government allocation to the health sector is relatively low in Bangladesh. [11] The effective delivery of services consists of efficiency of health professionals, sufficient allocation of budget, and the managerial efficiency of the organisation. With regard to allocation, the ADP report in Bangladesh states that US\$560 03 million was allocated for the 2010-2011 financial year to improve health, nutrition, population and family planning and to assist in achieving the goals of health for

\footnotetext{
${ }^{2}$ The Donor Consortium consists of international development organisations that work towards improving governance and health service delivery for developing nations such as Bangladesh. These organisations work in different health sectors in Bangladesh. For example, the United Nations Children's Fund (UNICEF) supports child health, immunisation and nutrition programs; the United States Agency for International Development (USAID) and the United Nations Population Fund (UNFPA) support family planning service delivery and population education; the World Health Organisation (WHO) is the main international source of technical assistance in the field of health supporting primary healthcare and maternal and health services; and the Asian Development Bank (ADB) provides support for health planning capacities. [9]
}

all including the targets of the MDGs. This amount is the equivalent of $37.3 \%$ of the total health budget and 5.68\% of the total budget of the country in the same financial year. This percentage of the development budget in the health sector has increased slightly from $37.3 \%$ to $41 \%$ in $2012-13$. [12] However, this amount is relatively small and inadequate to meet the necessary health goal of providing sufficient delivery of services. Data show that in 2006, the total health expenditure in Bangladesh was \$14 per capita, compared to $\$ 29$ per capita in India, and \$57 per capita in Sri Lanka during the same period. [13]

Good governance can be assessed by specific standards, including: transparency, accountability, efficiency, effectiveness, fairness, participation, predictability and ownership/engagement. $[14,15]$ Adhering to high standards of governance by implementing accountability for health service organisations can enhance the quality of health service delivery. Accountability of healthcare organisations can be implemented through political oversight and regulation. This study has examined the responsibility of elected officials to assess the quality of health service delivery and to understand and implement accountability for healthcare organisations.

The current status of accountability in health service delivery in Bangladesh has been evaluated in a few studies. Nurunnabi and Islam [16] conducted a quantitative study assessing accountability among privatised healthcare services in Bangladesh. This study showed that $30 \%$ of the respondents expressed concerns or doubts about the implementation of accountability of administrators and managers. A similar percentage of respondents reported that waiting time to get an appointment for services was lengthy; potential causes included the observation that nepotism in hiring weakened the effectiveness of administration and management. Mahmud [17] demonstrated that decentralisation of management and services and democratic decision-making contributed positively to community participation and the enhancement of quality healthcare. She also posits that decentralisation is perceived as a way to empower communities by engaging them in local level planning, resource mobilisation, and administrative and judicial authority. A study by Afsana [18] showed that laboratory tests and medications are not broadly available in many hospitals due to corruption and illegal private practice, consequently healthcare users have to spend extra money in order to obtain necessary assessments and treatments. Van [19] has examined three factors that can lead to corruption in healthcare delivery. These factors are: the lack of incentives and poor ethical tenets and values. Osman's 
[9] study suggests that managerial inefficiency is one of the causes, which contribute to inaccessibility of health facilities by unfairly distributing available healthcare resources and funding among rural and urban areas.

These studies have not identified and examined the role political actors and factors play in the implementation of health service delivery and the process of accountability. The objective of this study is to identify and examine the role elected officials in the delivery in health services and how politics contribute to or undermine accountability and quality of health service delivery. Local government elected officials should be responsible for supervising health professionals to promote quality healthcare delivery through ensuring accountability. Ensuring responsibility and providing authority may promote accountability; however authorisation of power through bureaucratic channels and the influence of politics over decision-making may limit health service accountability. This happens because of a lack of devolved power to locally elected officials. An assessment of the understanding of political responsibility by politicians and administrative responsibility by healthcare providers and how their understanding contributes to the promotion of accountability and quality of care can be obtained through the use of interpretive qualitative research methods. This paper presents the impact of understanding by politicians and healthcare providers of the role of politics on accountability and healthcare quality.

\section{Methodology}

A total of 68 in-depth interviews and five focus group discussions were conducted in two areas both rural (the Chhatak sub-district) and urban (the Savar sub-district) areas in Bangladesh. These two areas were selected based on socio-economic status and the progress of maternal and child health ${ }^{3}$ in Bangladesh. This study was conducted using in-depth interviews from the national level respondents (-8), health professionals (-37), locally elected representatives $(-7)$, and local informants (-16). In addition, five focus group discussions with a total of 39 respondents or service recipients were approached to collect input from service users in order to assess their understanding of how political action contributes to accountability and the quality of health service delivery.

Additionally, this study demonstrates a comparison of accountability and health service quality through examining the views of political actors of the two selected health service organisations. Secondary sources of data from the literature reviews were used in this study for understanding accountability in health service delivery. This study is a part of the author's Ph.D. project (Project no.5880), which was approved, by the Social and Behavioural Ethics Committee, Flinders University, Australia in 2012.

\section{Results and discussion}

Political responsibility and accountability in the delivery of high quality health services Political officials in this study stated that healthcare professionals are responsible and accountable for improving the quality of health service delivery. They also said that some of crucial political factors that affect the accountability of health service organisations (outlined Figure 2) include the items noted below. These factors have been analysed to better understand how political actions can contribute to accountability and the quality of health service delivery.

\footnotetext{
${ }^{3}$ The Dhaka district (the Savar sub-district) has the lowest human poverty index (26.51\%). Conversely, the Sunamganj district (the Chhatak sub district) has the highest human poverty index (39.44). [20] The Study by Sen and Ali [20] shows that the districts that have lower income poverty level, also tend to have a lower human poverty index, reduced child mortality and low fertility rates.
}

Figure 2: Factors influencing political responsibility and their impact on accountability and quality of healthcare delivery

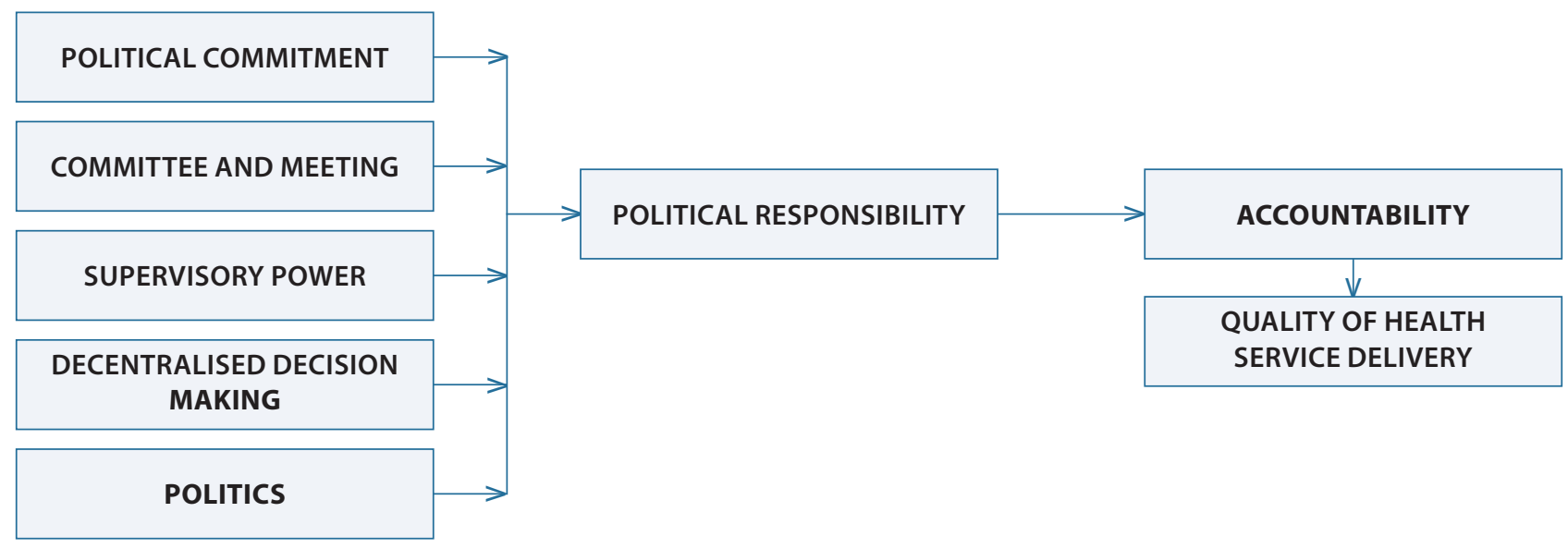




\section{The commitment of elected representatives}

Elected officials can make commitments to expect and demand accountability from healthcare providers and to abolish or minimise corruption among health professionals and organisations. Unfortunately, the leaders of their local political parties do not consider these issues and their impact on the quality of healthcare and their constituent population. Political candidates reportedly address healthcare improvements during election campaigns, but do not follow through with their promises after they are in office.

Though greater democratic governance has been witnessed in the past few years, no significant improvement has been noted in the areas of healthcare quality and accountability. Challenges identified include a lack of clarity about where the responsibility for this commitment should lie. For example, an elected representative of a rural health service organisation stated that the local Member of Parliament (MP) has expressed a commitment to enhancing the quality of health service delivery by promoting accountability. The local MP holds the highest position because his position is above that of secretary and the elected representatives at the local level work under the supervision of the MP. Therefore, he should take on this responsibility, a role designated for his position.

Similarly, the local elected representatives from the urban site argue that the MP likes organised meetings in order to highlight his name and promote economic development rather than focus on improvement of health service delivery. He is only perceived as being sincere when engaged in local activities, including when he visits hospitals to provide supervision. $\mathrm{He}$ is reported to recommend doctors for posting/transfer based on political influence or public complaints, but otherwise does not provide constructive suggestions to improve hospital environments.

\section{Health Service Committee}

The rural health service organisation has a health service committee under the supervision of local Member of Parliament (MP). This committee should play an important role in promoting high quality health service delivery, but the committee has no administrative authority to recruit doctors or transfer healthcare providers. The committee organises meetings occasionally, through each month, in which constructive discussion can identify issues and develop solutions to promote accountability and enhance quality in delivering health services. However, information from the rural UHC shows that this health services committee organised only two meetings in 2012.
Most elected officials are not willing to organise meetings to improve health service delivery as they have a very limited administrative authority to supervise health professionals. The provision of the existing local council does not allow elected representatives to supervise and monitor health officials as they are only able to play an observational role with health professionals. Elected officials are unable to execute public demands as they have limited authority. Scheduling regular meeting with a specific mission, and with identified goals, objectives, and agendas, allows the evaluation and identification of significant concerns and issues. A definition of criteria for accountability should be developed for local organisations, and periodic assessments should also be developed to evaluate compliance with implemented care standards and regulations.

An official source from the urban UHC argues that its upazila has a committee (Figure 3) in name only, but the committee was not functional for a long time. The local MP is required to establish the committee schedule, but the MP has no time to do so.

Therefore, a Health Service Committee is not functioning in urban health service organisations due to a lack of responsiveness by the MP, even though if falls in his job purview. However, the Upazila Parishad (UP) chairman conducts coordination meetings every month in which subdistrict level government officials, elected officials, NGOs, field level health workers, and local elites participate. [21] The coordination meeting acts as a guide for promoting accountability and ensuring quality of health service delivery.

Healthcare providers are formally accountable to their own department. Similarly, a UP member organises a ward meeting at the grassroots level to discuss the problems and prospects of health service delivery in addition to other local issues. Meetings at this level discuss the quality of antenatal services, the progress of immunisation, and the improvement of other maternal and child health issues. In fact, such meetings deal with the progress of health outcomes, but elected officials are unable to ensure the accountability of healthcare providers. One of the reasons for this is a lack of supervisory authority of field health service providers, which is discussed in the next section.

\section{Supervisory authority of elected representatives}

Involving elected representatives in overseeing the activities of health centres can be one of the ways to promote accountability and the quality of health service delivery, as the local elected representatives work very 
Figure 3: Committee of health service management of Savar and Chhatak upazila

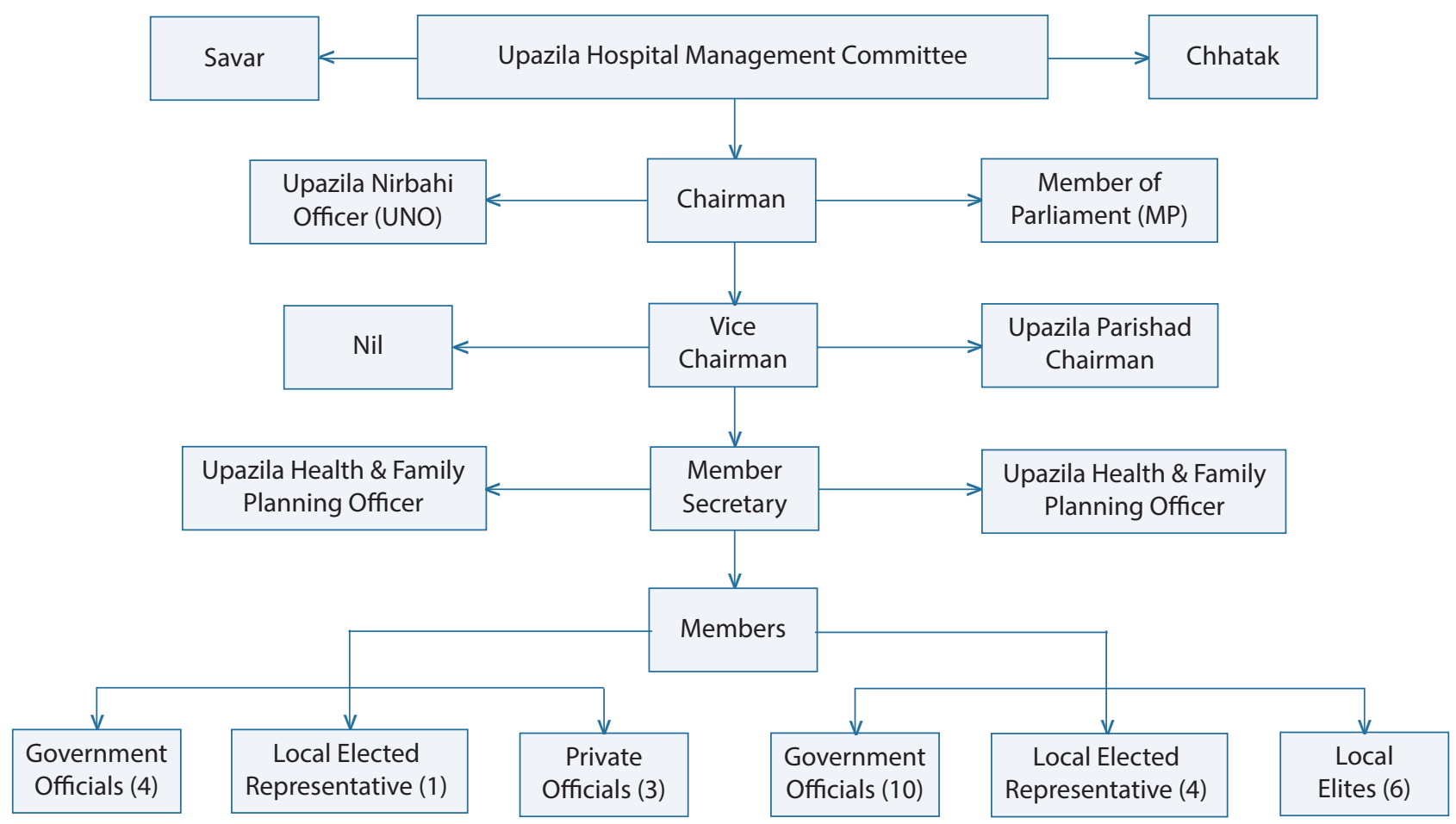

closely with healthcare providers. However, elected officials do not have the formal authority to supervise healthcare providers. For instance, the UP Chairman argued that the government should give sufficient authority to local elected representatives so that supervision can be improved to ensure the accountability of field healthcare providers. One of the mechanisms could be to require the health and family planning officials to report to elected representatives to ensure accountability. However, currently only the Health Department under which the health centre operates is administratively responsible for supervising the activities of the health centre. The Union Parishad or its Chairman is only able to observe their activities as they do not have the formal authority to supervise the activities of the health centre.

The local policy maker was disappointed with the physicians appointed ad hoc at the local community clinic and union sub-centre (USC), but does not have the authority to make necessary changes or hold the medical doctors accountable. He made efforts to make doctors accountable and keep them working in the hospital, but could not ensure their accountability as he has limited administrative authority to take necessary action (see Box 1.1). Local respondents in this study reported that the MP has taken action against mismanagement by doctors; as a result, doctors leave this hospital. Out of 20 doctors originally appointed to these facilities, only four doctors remain, limiting the patients' access to services.

\section{Box 1.1: Inadequate supervisory power affects accountability}

The local MP visited hospital, union sub centre and community clinic and noted the absence of doctors. Afterwards, he noticed the absentee and asked the reason of their absence. The MP also argues that it is not possible to ensure accountability of doctors providing excessive power to higher administration. The MP is the chairman of the health service committee but he cannot take action on mismanagement as he holds limited supervisory power. However, the minister can suspend, transfer and take necessary action because he has constitutional power.

[Source: Interview with local policy maker]

\section{Constructive politics}

The nature of politics and the attributes of politicians have an impact on accountability and the quality of health service delivery. Politicians in office report avoiding healthcare responsibilities because they perceive them as being under the jurisdiction of the state government.

Opposition political parties have limited access to the activities of health organisations in both rural and urban 
sub-districts, but they can bring attention to healthcare challenges and create awareness among the local politicians about the identified problems.

Unfortunately, most political parties have limited understanding of the issues and are not very interested in focusing on healthcare improvements. If the elected officials and opposition parties would collaborate to address these issues, society and the community would benefit.

The prevalent political culture is one of reasons for health professionals' poor accountability. Doctors are involved in politics through a powerful organisation that is connected with national leadership. This political influence allows them to avoid accountability. For instance, the doctors' association works as a powerful arm of the government and plays a significant role in changing health policy and doctor transfers.

Thus, the powerful leaders of doctor's association pay little attention to an MP's actions as they know the MP has insufficient power to take action against the mismanagement of doctors and field staff.

\section{Decentralised decision-making}

Policy makers have understood that the centralisation of decision-making is a major problem for the health sector. Decentralisation can make health service delivery more effective, accountable and transparent. Decentralisation means that health system at the local level have to be accountable to the locally elected governing body.

Unfortunately, the health system is not decentralised; one of the reasons is lack of political will of the centralised democratic government. Centralised officials oppose decentralisation because they do not want to share power with locally elected representatives.

Local level hospitals can provide improved quality of healthcare through local planning and resource management. But local hospitals still depend on the central government for resource allocation and expenditure. The central authority is loath to share power with the local level, including resource allocation to local healthcare organisations. The upazila Health Service Committee can be strengthened through decentralising power to the local level such as authorising the upazila parishad chairman to be able to make decisions for quality improvement.

But local doctors do not want to report to elected officials, believing that they have a poor understanding of hospital administration. For example, on one occasion these officials were called 'half educated or illiterate'. Doctors and healthcare professionals also fear that unqualified supervisors may interfere with the provision of healthcare and the doctor-patient relationship. Local officials will need to partner with expert doctors to develop guidelines and standards, and perhaps allocate the supervisor role to a qualified health professional and administrator.

\section{Conclusion}

The health system is not adequately decentralised, which reduces power of authority of elected representatives to fight against mismanagement and poor accountability. In addition, healthcare professionals are not willing to be accountable to elected officials, perceiving them to lack education and expertise and to easily succumb to political influence and corruption. Elected officials themselves have shown little commitment to promoting accountability and enhancing the quality of healthcare. Therefore, necessary authority should be designated at the sub-district and lower levels within local governments to promote accountability and quality in healthcare.

\section{Competing interests}

The author declares that he has no competing interests.

\section{References}

1. World Bank. Countries: Bangladesh, Topics: Health Indicators [accessed Oct 7, 2014]. World Bank; 2013. Available from: http:// data.worldbank.org/indicators\#topic-8,

2. Bangladesh Health Facility Survey (BHFS). Bangladesh Health Facility Survey (Revised Final Report February, 2012.) Columbia: University of South Carolina; and Dhaka: ACPR; New Orleans: Tulane University. 2012:15.

3. Chassin MR, Galvin RW. The Urgent Need to Improve Healthcare Quality. Institute of Medicine National Roundtable on Healthcare Quality. JAMA. 1998; 280(11):1000-1004.

4. Al-Qutob R, Mawajdeh S, Nawar L, Sadi S, Raad F. Assessing the quality of reproductive health services, The Policy Series in Reproductive Health, No.5. The Population Council Regional office for West Asia and North Africa; 1998.

5. World Bank. Developing Strategies for Improving Healthcare Delivery: Guide to Concepts, Determinants, Measurement, and Intervening Design. HNP Discussion Paper. 2010.

6. Ara F nd. Key issues to health governance in Bangladesh [accessed 10 July 2012]. Paper presented to the International Conference of Challenges of Governance in South Asia in Kathmandu, Nepal, December 15-16, 2008. Available from: <www.pactu.edu.np/ contents/project/files>.

7. Mridha MK, Anwar I, Koblinsky M. Public-sector maternal health programmes and services for rural Bangladesh. J Health Popul Nutr. 2009;27(2):124-138.

8. Directorate General of Health Services (DGHS), Health Bulletin 2014, Management Information System (MIS), Ministry of Health and Family Welfare, Government of the People's Republic of Bangladesh; 2014.

9. Osman FA. Health Policy, Programmes and System in Bangladesh: Achievements and Challenges, South Asian Survey, 2008;15(2): 263-288. 
10. Rahman MS, Ashaduzzaman ASM, Rahman. Poor People's access to health services in Bangladesh: focusing on the issues of inequality. Network of Asia- Pacific Schools and Institutes of Public Administration and Governance Annual Conference, China National School of Administration, Beijing; 2005.

11. Annual Development Program (ADP). Annual Development Programme 2010-11 [accessed 14 June 2012]. Planning Division, Ministry of Planning, Government of the People's Republic of Bangladesh; 2010. Available from: <www.plandiv.gov.bd >

12. Ministry of Finance (MoF). Budget in Brief 2012-13, Development Expenditure by Ministry/Division. Ministry of Finance, Government of the People's Republic of Bangladesh; 2013.

13. Planning Commission, Sixth Five Year Plan (FY 2011-FY2015), Accelerating Growth and Reducing Poverty (Part-2): Sectoral Strategies, Programs and Policies. Ministry of Planning. Dhaka: Government of the People's Republic of Bangladesh; 2011.

14. Woods N. The challenge of good governance for the IMF and the World Bank themselves. Journal of World Development. 2000 28(5):823-841.

15. Asian Development Bank, (ADB). Governance in the Pacific: Focus for Action, 2005-2009. Manila: Asian Development Bank (ADB); 2004.

16. Nurunnabi M, Islam SK. Accountability in the Bangladeshi Privatized Healthcare Sector. Inter J Healthcare Qual Assur. 2012;25(7):625-644.

17. Mahmud S. Citizen participation in the health sector in rural Bangladesh: perceptions and reality. IDS Bulletin. 2004;35(2):11-18.

18. Afsana K. The tremendous cost of seeking hospital obstetric care in Bangladesh. Reproductive Health Matters. 2004;12(24):171-180.

19. Van. Review of corruption in the health sector: theory, methods and interventions. Health Policy Plan. 2008;23:83-94.

20. Sen B, Ali Z. Spatial inequality in social progress in Bangladesh. Programme for Research on Chronic Poverty in Bangladesh (PRCPB), Working Paper-1. Dhaka: Bangladesh Development Studies (BIDS); 2005.

21. As-Sabe S, Hossain K. Call centres and their roles in e-governance: a developing countries perspective, The Journal of Community Informatics. 2008;5(3). 